REVISTA CHILENA DE LITERATURA

Noviembre 2009, Número 75, $115-128$

\title{
CONFIGURACIÓN DEL YO Y POLÍTICAS DE GÉNERO EN LA HYBRIS DE ALICIA GENOVESE ${ }^{1}$
}

\author{
Alicia Salomone \\ Universidad de Chile \\ aliciasalomone@yahoo.com
}

RESUMEN / ABSTRACT

Este trabajo tiene por objetivo analizar el poemario La Hybris (2007) de la escritora argentina Alicia Genovese, considerando la configuración del yo lírico y, asimismo, el tipo de política genérico-sexual que éste despliega. En este marco, es relevante revisar los sentidos que asume el juego de intertextualidad con la tragedia griega que propone el discurso del poemario. Ello se relaciona, por una parte, con la necesidad de confrontar un presente que se avizora complejo y confuso desde una tradición cultural que aporta construcciones ideológicas y sensibilidades comunitarias que pueden confrontarse con el propio contexto. Por otro lado, el juego intertextual posibilita dar sustento y legitimidad a una voz lírica que no solo expone la furia de ciertos padecimientos, sino que procura, dificultosamente, encontrar modos para que ese malestar se canalice de modo productivo.

PALABRAS ClAVE: poesía, literatura argentina, escritura de mujeres, estudios de género, Alicia Genovese.

This article aims to analyze La Hybris (2009), a poetry book by the Argentine writer Alicia Genovese, considering the configuration of the lyric subject as well as the gender politics developed in the text. In this frame, it is relevant to observe the role of intertextuality, in particular, the dialogue established between the tradition of classic tragedies and the poems'discourses. The hypotesis of this work mantains that, referring to Greek tragedy, the

1 Este trabajo se enmarca en el desarrollo de los Proyectos DI (U. de Chile) $\mathrm{N}^{\text {os }}$. 07/16-2 y $06 / 23-2$. 
poems may confront a present that is perceived both complex and confused. On the other hand, intertextuality functions as a way to give support and legitimacy to a lyric voice that not only aims to expose the fury caused by pain but also aspires to canalize her feelings productively.

KEY WORDS: Poetry, Argentine literature, women's writing, gender studies, Alicia Genovese.

En un texto crítico publicado en 2003, Alicia Genovese propone una cartografía poética de la década de los noventa en la Argentina, leyendo su diferencia desde un conjunto de rasgos específicos ${ }^{2}$. En el plano enunciativo, ella destaca la hibridación creciente entre el discurso de la poesía y el que se encuentra alojado en otros soportes textuales, particularmente en los mass media, poniendo en evidencia las condiciones y tensiones en las que opera hoy la representación de lo real. Por otro lado, desde el nivel del enunciado, observa en los textos las continuas remisiones a la violencia política de los años de la Dictadura, la que se manifiesta desde la mirada nueva: la que aporta la generación de los hijos de los desaparecidos, entregando una perspectiva impiadosa sobre la violencia pública y privada en la Argentina contemporánea. Alicia Genovese nos insta, asimismo, a leer la poesía de los noventa en vínculo genealógico con la producción de la década previa, la que al tiempo que constituye su punto de partida es también el espacio desde el que busca su distinción identitaria.

En los ochenta, lo que aconteció fue el inicio de la rearticulación de un campo intelectual que había sido devastado por el poder militar instituido el 24 marzo de 1976, y, por eso mismo, el corpus poético de esos años inevitablemente porta una huella de índole post-dictatorial y postraumática; la que entendemos, desde la propuesta de Idelber Avelar, como la incorporación reflexiva, en el sistema de determinaciones de los textos, de la derrota inflingida, en el país y la región, a un proyecto de transformación radical de las estructuras sociales y políticas (Avelar 28-29). Por otra parte, en términos de las propuestas estéticas, como señala Genovese, lo que tiene lugar es la configuración de ciertos sistemas de poéticas: neobarrocas, neorrománticas,

2 Otra aproximación, si bien menos crítica frente al mismo escenario poético, se encuentra en Tamara Kamenszain (2007). Para una visión panorámica a la poesía de la postdictadura, desde los aportes de diversos autores (as), ver Fonderbrider. 
objetivistas (Genovese 202). Y, finalmente, también es necesario referir a ciertas materialidades: libros, revistas, encuentros, editoriales; fenómenos que, en su copresencia y mutua implicación, dieron un tono y una dinámica particular al espacio poético de esos años, que se proyecta hasta la actualidad.

Un ámbito escasamente visibilizado por la crítica, e incluso no siempre reivindicado por las propias autoras, aunque claramente distinguible desde los ochenta en adelante, es la conformación de un territorio escritural de mujeres ${ }^{3}$. Un espacio que, en diálogo más o menos libre con las distintas poéticas mencionadas antes, instala un conjunto de voces polemistas, que surgen en las obras de autoras como Diana Bellesi, Irene Gruss, María del Carmen Colombo y la propia Alicia Genovese, entre muchas otras. En ese corpus, lo que puede observarse es, por una parte, la definición de una praxis escritural plural que, a la vez que discute identidades y roles sexogenéricos tradicionales, indaga en la creación de nuevos lenguajes poéticos. Por otra parte, llama la atención cómo las autoras toman posición frente a la tradición literaria argentina; y en particular, respecto de esa zona que agrupa a una serie de mujeres disidentes, desde Alfonsina Storni a Alejandra Pizarnik, con quienes las poetas de la postdictadura se perciben genealógicamente vinculadas.

A partir de los noventa, la vitalidad del espacio poético no decae pero difumina sus contornos estéticos hacia una poética de la mezcla y la contaminación, que opera trasvasijes entre distintas modalidades enunciativas: desde la parodia o la ironía a las nuevas formas de lirismo, desde los reposicionamientos del realismo hasta una reapropiación, a primeras luces extemporánea, de la literatura clásica (Genovese 202) ${ }^{4}$. Por otro lado, en lo que hace a las subjetividades representadas, se descubren hablantes

3 Para un desarrollo más amplio de este tema, ver Genovese, La doble voz...

4 La vuelta hacia los clásicos no es un rasgo infrecuente en la poesía actual, pero tampoco lo es en el corpus de la poesía latinoamericana moderna. Para Ángel Rama (Transculturación narrativa), este tipo de fenómenos transculturadores son característicos en nuestra literatura, sobre todo a partir de las vanguardias, y operan como un modo de instalar asuntos que tienen directa relación con el contexto de producción de las obras, pero apelando a una estrategia que, mediante el distanciamiento temporal y/o espacial, hace viable la circulación de discursos que no pueden (o no quieren) ser enunciados de manera directa. En el mismo sentido, la recuperación de ciertos mitos presentes en la tradición clásica puede ser útil a la hora de evidenciar ciertas exclusiones que, desde el punto de vista del género, etnia o clase, se ocultan tras la pretendida universalidad del proyecto moderno. Ver Rama. 
poéticos/as que se descentran y se multiplican, ejecutando una performance de desplazamiento o nomadismo constante, que expande una perspectiva, ya visible en los ochenta, de cuestionamiento de las identidades y subjetividades fijas o totalizantes. Un rasgo que puede seguirse de manera específica en las producciones de mujeres, y en particular en la de aquéllas que, como las de Bellesi o Genovese, explicitan un lugar de enunciación crítico frente al ordenamiento socio-cultural androcéntrico y etnocéntrico.

Pero Alicia Genovese no solo es capaz de dar cuenta agudamente de las coordenadas poéticas de la postdictadura. Como creadora, ella también forma parte de la constitución de ese espacio, el que prolonga con la publicación de un último poemario: La Hybris (2007), que la poeta decide anclar en un concepto recuperado de la tradición dramática griega. El libro se organiza en tres partes: "El mundo inferior", "La discordia" y "La tierra del desorden", cada una de las cuales se compone de un conjunto variable de poemas breves, algunos de una sola palabra, y que por lo general no exceden los treinta versos. Poemas que se construyen desde una rítmica precisa, casi cortante, y una condensación semántica elevada, lo que logra dotar de alta eficacia estética a cada uno de los textos.

Las diversas partes del libro están precedidas de ciertos epígrafes, cuyos ecos clásicos, lejos de desterritorializar las problemáticas del texto, refractan sobre el contexto que lo hace posible: la escena socio-cultural argentina de las últimas tres décadas, la que se muestra atravesada por profundos traumas y quiebres, tanto a nivel individual como colectivo. Así, en diálogo con una tradición de tanto peso como la cultura clásica, auténtico reservorio de construcciones ideológicas y sensibilidades comunitarias que pueden confrontarse con un presente que se avizora como confuso y doloroso, la hablante logra escapar de su encasillamiento en una enunciación eminentemente particular para dar cuenta de una experiencia que, además de individual, es social ${ }^{5}$.

5 La lingüista Patricia Violi analiza cómo, a nivel del discurso, el sujeto masculino y el femenino no ocupan la misma posición ni tienen la misma fiabilidad, pues la relación que los une es la derivación: lo femenino deriva del Otro, que lo absorbe, definiéndolo como su polo negativo. Si lo masculino cubre al mismo tiempo la posición de término específico para uno de los dos sexos y del genérico, que vale para la universalidad del género humano, esta posibilidad es negada a lo femenino, que solo puede nombrar una parcialidad o una individualidad específica. Bajo esta trama discursiva-ideológica, para acceder a la universalidad del lenguaje y de la historia, las mujeres tienen que suprimir la forma de su propia singularidad, lo que supone para ellas un continuo desplazamiento entre la "persona" y la "mujer": entre 
Ese juego intertextual posibilita, asimismo, dar sustento y legitimidad a una voz que no solo expone la furia de ciertos padecimientos sino que procura, dificultosamente, encontrar modos para que ese malestar se canalice de modo productivo. Y, precisamente, ello es lo que explica, por un lado, las inserciones de la tragedia antigua, a través de las citas a la Antígona de Sófocles y a las Erinias de Esquilo, así como sus reverberaciones modernas en la Medea de Christa Wolf; y, por otro lado, las referencias a Heráclito, el filósofo presocrático que inaugura las concepciones polemológicas del mundo, situando al conflicto, no como caos, sino como el motor que dinamiza el orden social y cosmogónico ${ }^{6}$.

Volviendo a la noción de hybris, es preciso recordar que se trata de un concepto de connotación negativa en la cultura griega, por su asociación con la desmesura, la violencia y el desorden, lo que otorga a su significado un sentido de conmoción o locura que, al mismo tiempo, implica una impureza. La hybris podía visibilizarse de múltiples maneras: desde ciertos actos que dejaban traslucir el orgullo aristocrático o el placer en la ostentación de la riqueza, hasta aquéllos que hacían manifiesto el descontrol emocional y la irracionalidad. De este modo, la hybris llegó a simbolizar la arrogancia humana que buscaba apropiarse de lo que era prerrogativa de los dioses, instituyéndose en el pecado por antonomasia, en tanto alteraba un mundo que se creía sustentado en el orden, la justicia y el destino ${ }^{7}$. Por eso mismo, toda

el plano emotivo-sexual y el intelectivo-cultural; en definitiva, entre el lugar de "objeto de discurso" en que las sitúa el lenguaje, y la posibilidad de acceder dificultosamente a la posición de "sujeto". Para Violi, esta posibilidad pasa necesariamente por la elaboración de la propia diferencia genérico-sexual, entendida como un proceso que permite relacionar la singularidad específica de cada existencia con la forma general de las representaciones, haciéndose palabra, discurso, lenguaje. Este proceso, que es a la vez individual y colectivo, es lo que permitiría ir desde el yo al "nosotras" y desde el "nosotras" a la infinita multiplicidad de un yo singular. Ver Violi.

6 Octavio Paz define la concepción polemológica de Heráclito desde la idea de que el universo está en tensión, como las cuerdas de un arco o una lira: el mundo "cambiando, reposa". Pero Heráclito no solo concibe el ser como devenir -idea en cierto modo implícita en la concepción de la épica- sino que hace del hombre el lugar de encuentro de esa guerra cósmica (Paz 201-2).

7 Dice Octavio Paz, citando a Werner W. Jaeger, que lo que caracterizaba al espíritu griego, a diferencia del de los pueblos anteriores, era su conciencia de que existía una legalidad inmanente en las cosas. Una idea que se relaciona, por un lado, con una concepción dinámica del cosmos, como un todo animado por leyes, impulsos y ritmos cósmicos; y, por otro lado, con 
manifestación de hybris requería de un castigo ejemplar que, a través de la némesis, devolvería el aidós o equilibrio perdido, reinstalando el imperio de la sophrosyne: un ideal de templanza y dominio de sí que buscaba educar la voluntad en el control de los impulsos instintivos, y que logró su expresión discursiva bajo la fórmula "nada en demasía".

La crítica feminista suele poner la mira en el modo en que la naturalización de ciertos rasgos culturalmente asociados a lo masculino o femenino juega un papel ideológico crucial en la determinación de los roles sociales asignados a varones y mujeres. Desde esta óptica, es interesante observar el clivaje sexo-genérico que evidencian las nociones de hybris y sophrosyne en la cultura y sociedad griegas. Al respecto, el historiador Jean Pierre Vernant sostiene que la idea de sophrosyne, según se asumió en el proceso de democratización de las ciudades-estado griegas a partir del siglo VI a.C., posee un perfil masculino o virilizante. Lo que él explica apelando al origen histórico de este ideologema, ligado al sentido de disciplina impuesto a los soldados con el objeto de que se sintieran vinculados en la batalla como miembros de una sola familia (Vernant 49-50). Así, mientras la templanza se valoró como una virtud masculina, la hybris, por su cercanía con los excesos y el desmadre pasional, tendió a ser identificada en el polo semántico de lo femenino. Un argumento que contribuyó, en no escasa medida, a la exclusión de las mujeres del espacio de la polis y a su relegación a un papel subalterno al interior del oikós o casa patriarcal.

La helenista Elena Huber, en su estudio del discurso de los personajes femeninos en la tragedia clásica apunta, sin embargo, una aguda observación acerca de la distinción entre hybris y sophrosyne que complejiza y tensiona esta polaridad. Para Huber, el lexema hybris evidencia, en muchos textos dramáticos, un alto grado de flexibilidad para delimitar las distintas funciones derivadas del género-sexual, lo que ella descubre a partir de la ubicación estratégica que asumen estas ideas en contextos de enfrentamiento entre varones y mujeres. Así, sugiere que ni la idea de hybris, ni la de kakia (maldad), deben ser entendidas como conceptos fijos o unívocos, en tanto eran calificaciones

la noción del hombre como parte activa de esa totalidad, lo que conlleva su responsabilidad frente al mantenimiento de un orden cuya legalidad conoce. Para Paz, es precisamente esa tensión contradictoria entre determinación y libertad lo que está en la base de lo heroico y de la conciencia de lo trágico (Paz 201-2). 
que cada género-sexual podía adjudicar al otro frente a la violación del espacio y tiempo propios, así como de sus funciones privativas ${ }^{8}$.

Desde la consideración de la polisemia de la palabra hybris, es posible dirigir ahora la mirada al poemario de Alicia Genovese para observar cómo esa noción se resignifica desde una furia femenina y contemporánea, y, asimismo, para determinar cuáles son los sentidos que ella adquiere en la palabra de la hablante. Lo primero que hay que precisar es que no estamos ante un sujeto lírico que se mantiene unificado y el mismo a lo largo de todo el texto. Por el contrario, lo que allí encontramos es una amplia diversidad de subjetividades femeninas que se configuran, espejeadamente, en una experiencia de dolor que se manifiesta desde la puesta en acto de una voz furiosa, de una protesta. Desde esta óptica, es posible descubrir un conjunto de figuras cuya identidad se articula mediante una actuación o performance ${ }^{9}$ que escenifica una serie de movimientos y voces, apelando a un juego de máscaras que fractura la unidad del $\mathrm{yo}^{10}$. Una estrategia "de entrada y salida", como la califica la hablante, que le permite a aquél aliviarse de su padecimiento a través del desplazamiento nomádico entre distintas posibilidades de instalación subjetiva:

\author{
Una máscara \\ para entrar y salir \\ de mí,
}

8 Desde esta concepción dinámica de la relación entre hybris y sophrosyne se hace verosímil y aceptable la palabra furiosa de Antígona en su enfrentamiento con el poder tiránico de Creonte. Y es precisamente esta figura la que elige Genovese para iniciar su poemario, retomando las palabras de Antígona en un diálogo con su hermana: "Deja que yo y éste mi desatino corramos ese riesgo" (Genovese, La Hybris 7).

9 Para Judith Butler, la identidad género sexual no es una esencia inmutable sino un resultado performativo; es decir, surge como consecuencia de la repetición estilizado de actos que los sujetos ejecutan, compelidos por la sanción social y el tabú. Al mismo tiempo, esa misma actuación, en las múltiples posibilidades que ofrece de habitar el cuerpo y el género, es la que abre la posibilidad de modificar las pautas culturales recibidas. Ver Butler.

10 Etimológicamente, el vocablo "máscara" se vincula a careta (1495) y a persona disfrazada (1605). A su vez, deriva del árabe máshara: bufón, payaso, personaje risible, palabra que habría sido influida por otra del italiano dialectal: masca o bruja (643), la que a su vez posee un antiguo origen germánico o celta. El disfraz, por su parte, se asocia al enmascaramiento y al disimulo, al despistar y borrar las huellas (Corominas 384-385 y 217). 
sorber

desilusión y furia

máscara, ese otro mín ${ }^{11}$ (Genovese, La Hybris 53)

Respecto de la misma operatoria, Jorge Monteleone sostiene que es en esta relación matriz entre la máscara y la ira como va tomando forma una enunciación femenina que, proyectando su presencia, procura instalar una singularidad o identidad personal. La que, sin embargo, no es trascendente ni esencial, pues deja explícita la distancia entre el yo y esa serie de figuras retóricamente construidas que ocultan su rostro: la resentida, la excluida, la golpeada, la incongruente, la atrapada, la sedienta, la sacrificial, entre varias otras (Montoleone). Es la presencia de esas imágenes lo que, por su parte, le hace pensar a Juan Fernando García que ellas son una suerte de símil de las "locas mujeres" de Gabriela Mistral. Desde mi punto de vista, sin embargo, esta proposición no es sostenible pues, si lo que encontramos en los poemarios mistralianos son subjetividades femeninas que, en su otredad radical, asumen la sinrazón poética o la misma disolución identitaria como única representación posible dentro de una simbólica androcéntrica que las excluye, en el texto de Genovese, en cambio, las sujeto que hallamos son distintas. Se trata de mujeres que, transitando por las estaciones de una pasión dolorosa derivada de las múltiples agresiones de que son objeto, buscan, sin embargo, puntos de fuga: recodos reflexivos que les permitan rearmarse como personas y proceder a la impugnación de aquello que les provoca una herida o les evoca el dolor. De este modo, a través de una multiplicidad de estrategias, que van desde la admonición y la denuncia hasta la ironía o el discurso propositivo, ellas logran articular un "no" e instalar una poética de la resistencia. Un juego que inevitablemente involucra la pasión pero que, al mismo tiempo, no reniega del ejercicio racional: un recurso que resulta imprescindible en todo distanciamiento de carácter crítico, incluyendo cualquier proposición de índole irónica y/o cuestionadora del "orden del discurso".

Ni la refutación oratoria

ni el movimiento esperable

11 En adelante, las referencias al texto se incluyen entre paréntesis a continuación de la cita. 


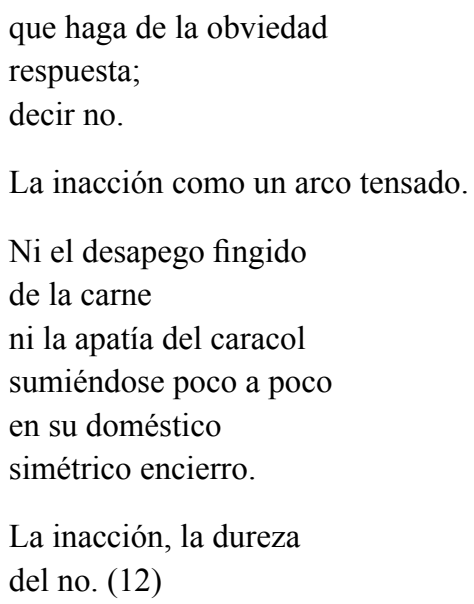

Para esta hablante furiosa, que se atreve a "padecer", pero que, al mismo tiempo, logra observarse, desdoblándose a sí misma, en los papeles que asume en las distintas escenas del sometimiento y el maltrato, la posibilidad de la escritura se revela crucial. Pues es precisamente la palabra el modo que encuentra como el más idóneo para objetivar la resaca emocional, para ponerla enfrente, para nombrarla con todas sus letras, haciendo a través de ella el intento pragmático de expulsar de sí el dolor: "decir no" (12), "Escribir..." (13), "Me retiro muda / de esta competencia" (19). Un gesto que, sin embargo, ella quiere despojado de todo modo simple o inconsciente del olvido: esa denegación de la herida proferida sobre el yo que condenaría a la sujeto a una eterna repitencia. Una posibilidad sobre la que ella misma se interroga en el poema "La incongruente":

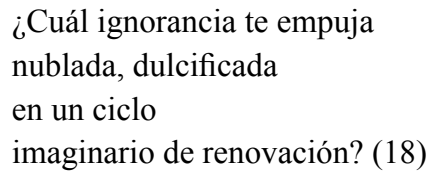

Denegación cuyas consecuencias nefastas deja crudamente expuestas en "La golpeada":

\author{
Solo para compensar \\ la brusquedad \\ te echan dulzor en los oídos,
}




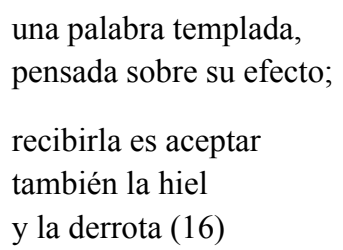

En este escenario, la escritura aparece como un ejercicio de procesamiento, como una praxis que trabaja de forma reflexiva e intensa: en un ida y vuelta entre la materia primaria de las emociones devastadoras y la posibilidad de operar estratégicamente sobre ellas, intentando una reconstitución de la propia subjetividad desde la base del ejercicio sanador de la memoria.
La palabra
limpia el miedo;
$[\ldots]$
Escribir, la hechura
de palabras
cauteriza la herida, sin la simpleza
del olvido. (13)

catarsis, oh ese drenaje (15)

Instalado en esta política de escritura, el discurso que articula el poemario de Alicia Genovese no puede regodearse en la exposición fenoménica de la violencia sobre las sujetos $\mathrm{y}$, mucho menos, apelar a un tratamiento victimizado y/o idealizado de sus figuras. En el mismo sentido, tampoco asume la idea de hybris desde la perspectiva a la que echa mano cierto feminismo, cuando rescata, con valor invertido, ciertos estereotipos que históricamente han pesado de forma negativa sobre la mujer, como la pasión o la locura ${ }^{12}$. Por el contrario, en su reapropiación de aquella noción, lo que hace el texto

12 Aludo aquí a ciertas tendencias, que pueden rastrearse en algunos sesgos de Julia Kristeva o Hélène Cixous, por ejemplo, que utilizan las representaciones culturales de la locura o la pasión como base para una política de afirmación de la diferencia femenina. Alicia Puleo ha contestado estas perspectivas, destacando el riesgo que representa para el feminismo 
es entregar una reflexión crítica e incardinada (que liga mente y cuerpo) acerca de los efectos que sobre los y las sujetos engendra la violencia de un sistema socio-cultural que oprime y discrimina desde múltiples determinaciones sociales y sexo-genéricas. Una trama que si, desde un lado, supone la desmesura y el abuso de quien detenta mayor poder en la polaridad jerárquica dominador/dominado, desde el otro extremo también reproduce la violencia, condenando a quien se encuentra en el lugar del sometido al estancamiento en una rabia auto-anulatoria, que incapacita a quien la padece para proyectarse en un impulso transformador de los vínculos personales y sociales.

Desde mi perspectiva, es esta reflexión la que estructura el texto, y la que se textualiza en el tránsito que la hablante despliega por los distintos escenarios por los que ella se desplaza. Sean éstos los eminentemente privados o íntimos, que dominan en las primeras dos partes del poemario, donde se dibuja, una y otra vez, una hablante atrapada en una performance erótica intervenida por relaciones desiguales de poder. O bien, el propio espacio de la urbe, campo privilegiado de la disputa hegemónica por la reapropiación de los signos y del poder social en su conjunto. Este último, un ámbito al que finalmente la hablante accede en la sección titulada "La tierra del desorden", con el objetivo de hablar por otras. Es decir, para asumir la representación o para dar testimonio por esas sujetos silentes que encarnan una rebeldía femenina que, a diferencia de otras menos productivas, logra hacerse palabra y acto, en el anudamiento entre el desgarro personal, la memoria y la conciencia política. Unas mujeres que, en la Argentina contemporánea, no pueden ser sino aquéllas que, definidas desde el doble nombre, provocador e irónico por la inclusión del apelativo que les inflingió la Dictadura, de madres y "viejas locas" de Plaza de Mayo, irrumpen como Erinias, activas y furiosas, en un espacio público colonizado por la barbarie de las armas y los signos para reapropiarlo simbólica y materialmente desde el reclamo de justicia por el crimen atroz perpetrado en los cuerpos de sus hijos.

\author{
Madres, \\ emplazados pañuelos \\ para hijos ausentes; \\ se feminiza el cuerpo en el dolor
}

contemporáneo la afirmación de una moral de la transgresión que, al cabo, puede revertir en una reafirmación del statu quo. Ver Puleo. 


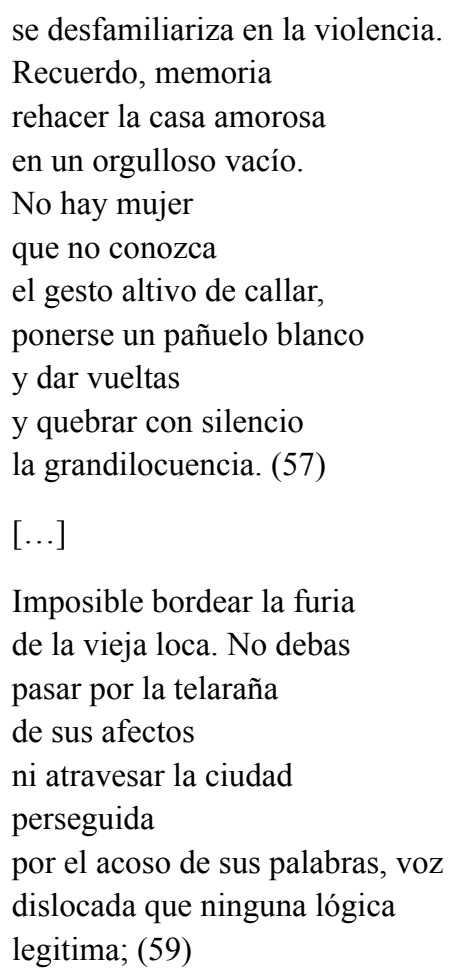

Y es precisamente junto a estas figuras culturalmente desajustadas: maternas y rebeldes, iracundas y políticamente justicieras, violentas y amorosas, domésticas y públicas, silenciosas pero elocuentes: viejas locas de "voz dislocada" e ilegítima. Es de allí desde donde la hablante puede encontrar un anclaje para regresar con su yo al texto, como una acompañante amorosa que es arrastrada al escenario de una lucha, en la que, al mismo tiempo, se ve forzada a reposicionarse de manera autónoma. ¿Sucumbir ante la furia? ¿Malograrse por “exceso de control”? ¿Cómo situarse frente a estos procesos traumáticos, los individuales y los colectivos? Son éstas las preguntas que acosan a la hablante en medio del remolino personal e histórico. Si por momentos ella parece sucumbir a su propio desborde, perdiendo "ese sabio equilibrio / que Jane Austen le daba" (58), finalmente logra retomar su curso hasta encontrar una salida, la que no puede sino situarse nuevamente del lado de la escritura. Pues, si antes vimos a la palabra poética expuesta como el recurso indispensable para asegurar la supervivencia de la hablante, en el final 
del texto el lenguaje se llena de sentido proyectual, desde la asunción de la poesía como un campo (quizás, el único campo) que hoy posibilita desplegar una praxis que, al tiempo que es estética, es también crítica y política.

\author{
Hybris. \\ que la furia \\ no dé nombre a las cosas \\ que las envuelva con su pulso \\ que las aguijonee el contraviento \\ que el aguijón no se clave en tu cabeza \\ que la conmoción \\ no te exilie \\ que la violencia genere un ritmo \\ que la ironía no lo clausure \\ construir una palabra \\ Para llamar, llamar (61)
}

"Construir una palabra / para llamar, llamar" (61), dice la hablante en el cierre del poemario. Desde este enunciado, no puedo menos que significar el texto desde un deseo que excede la furia y la ironía, y que busca en el lenguaje poético un espacio para la ideación de nuevos mundos y de nuevos modos de existencia. Un impulso de cambio y utopía que se llena de promesa en una enunciación que parece llamar a la transformación del modo estéril y terrible que aún domina en los vínculos humanos. Un deseo o un proyecto para el cual, como ella lo sabe, aún no disponemos de palabras, pero que puede (y debe) empezar a delinearse a través de la poesía.

\title{
BIBLIOGRAFÍA
}

Avelar, Idelber. Alegorías de la derrota: la ficción postdictatorial y el trabajo de duelo. Santiago de Chile: Cuarto Propio, 2000.

Butler, Judith. “Actos performativos y constitución del género: un ensayo sobre fenomenología y teoría feminista". Debate Feminista 18 (1998):

Corominas, Joan. Breve diccionario etimológico de la lengua castellana. Madrid: Gredos, 2000.

Fonderbrider, Jorge. Ed. Tres décadas de poesía argentina: 1976-2006. Buenos Aires: Eudeba, 2006. 
García, Juan Fernando. “Ecos clásicos, voz contemporánea”. Revista Ñ sábado 16 de febrero de 2008, versión electrónica http://www.bajolaluna.com/bajo\%201a\%201una\%202/ la\%20hybris\%20prensa.html

Genovese, Alicia. La hybris. Bajo la luna: Buenos Aires, 2007. La doble voz. Poetas argentinas contemporáneas. Buenos Aires: Biblos, 1998. "Marcas de graffiti en los suburbios: poesía argentina de la postdictadura". Revista Iberoamericana 202 (2003): 199-214.

Huber, Elena. "El espacio sociocultural del género en la poesía de Safo". En Elisabeth Caballero, Elena Huber y Beatriz Rabaza (editoras), El discurso femenino en la literatura grecolatina. Rosario: Homo Sapiens, 2000. 133-144.

Kamenszain, Tamara. La boca del testimonio. Lo que dice la poesía. Buenos Aires: Norma, 2007.

Monteleone, Jorge, "Entre la máscara y la ira". $A D N$. Suplemento de cultura del diario $L a$ Nación, sábado 22 de marzo de 2008, versión electrónica,

http://adncultura.lanacion.com.ar/Nota.asp?nota_id=996738\&high=genovese.

Paz, Octavio. El arco y la lira. El poema. La revelación poética. Poesía e historia. México: Fondo de Cultura Económica, 1972.

Puleo, Alicia, "Moral de la transgresión, vigencia de un antiguo orden". En: http://www.unb. $\mathrm{br} / \mathrm{ih} / \mathrm{his} / \mathrm{gefem} / \mathrm{labrys} 10 /$ espanha/puleo.htm .

Rama, Angel. Transculturación narrativa en América Latina. México: Siglo XXI, 1987.

Vernant, Jean-Pierre. Los orígenes del pensamiento griego. Buenos Aires: Eudeba, $4^{\mathrm{a}}$ edición, 1976.

Violi, Patricia. El infinito singular. Madrid: Cátedra, 1991. 